\title{
A Identidade Nacional Portuguesa: Conteúdo e Relevância*
}

\author{
Manuel Villaverde Cabral
}

\begin{abstract}
questão das identidades - pessoais ou coletivas, sociais, locais A ou nacionais - é sem dúvida das mais controversas, levantando problemas filosóficos e epistemológicos demasiadamente mal resolvidos até hoje, na minha opinião, por resvalarem com excessiva freqüência para o essencialismo identitário. Foi por isso, creio eu, que a historiografia convencional se manteve cética e mesmo distante perante a questão das identidades.
\end{abstract}

Só há cerca de um quarto de século, com a erosão paulatina do paradigma da história estrutural da primeira Ecole des Annales, correlativa por seu turno à erosão das clivagens políticas tradicionais subjacentes à formação da maioria dos atuais regimes representativos ${ }^{1}$, é que a questão da identidade nacional começou a adquirir, sob a influência crescente da antropologia e da sociologia pós-modernistas ${ }^{2}$, um papel cada vez mais importante na pesquisa e interpretação historiográficas.

\footnotetext{
* Este texto foi inicialmente escrito a convite do professor Luís Adão da Fonseca para a Mesa-redonda sobre Identidades Nacionais no Mundo Luso-Brasileiro da Sessão de História do Congresso Brasil-Portugal realizada em Salvador, Bahia, 22-24 de novembro de 2000 .
}

DADOS - Revista de Ciências Sociais, Rio de Janeiro, Vol. 46, n-3, 2003, pp. 513 a 533. 
Permanece irresolvida, contudo, no estudo das identidades nacionais modernas a controvérsia acerca do primado da Nação sobre o Estado ou deste sobre aquela. E mais complexo ainda é, seguramente, o estatuto das identidades antigas, isto é, anteriores à Revolução Americana, à ativação política explícita do patriotismo pela Revolução Francesa e, posteriormente, pela eclosão de movimentos de independência nacional desde o século XIX até ao período da chamada Descolonização.

\section{INSTRUMENTALISTAS, PRIMORDIALISTAS E CONCILIADORES}

Com efeito, parecem-me incontornáveis alguns dos argumentos que não todos - dos autores que, como Ernest Gellner (1993), conferem ao Estado uma espécie de primado empírico sobre a Nação e a correlativa identidade, que surgiria então como o resultado - por assim dizer, compensatório - de processos de aculturação individualizantes e desenraizadores como a urbanização, a industrialização e a própria alfabetização, em suma, aquilo a que, na sociologia histórica, se dá vulgarmente o nome de modernização.

Para Gellner, como é sabido, o primado do Estado sobre a Nação, que de algum modo reduz as chamadas identidades nacionais a uma dimensão virtualmente instrumental, pode ser resumido em mensagens de cariz algo provocatório como: "Dêem-me um Estado e eu vos darei uma Nação" ou "As etnias de hoje são nações mal sucedidas; as nações de hoje mais não são do que etnias bem-sucedidas!" (idem).

Do mesmo modo, porém, são dificilmente refutáveis alguns dos argumentos - que não todos, também - daqueles que, como Anthony Smith (1986), defendem que nenhuma elite guerreira, cultural e/ou econômica seria suscetível de fundar um Estado se as "massas" que essa elite pretende representar e dirigir não possuíssem, à partida, uma qualquer identidade coletiva referida ao território objeto desse Estado. Resta saber se esta última corresponde, efetivamente, àquilo que os defensores do nacionalismo cultural e político designam como identidade nacional.

Uma versão extrema dessa corrente essencialista - mais adequadamente designada, porventura, como primordialista, conforme sugere Paul Brass (1994) - pode encontrar-se, por exemplo, em um livro do antropólogo de origem catalã Josep Llobera, com a sua introdução da 
noção de "potencial étnico" contra qualquer idéia de "invenção da tradição". Com efeito, logo de início, Llobera introduz essa "idéia de um potencial etnonacional como um conceito fundamental" da sua teoria, acrescentando imediatamente que: "O potencial etnonacional aparece no período moderno como um dom: uma região tem esse potencial ou não o tem" (Llobera, 1996:13, ênfases minhas).

E para que não subsistam dúvidas quanto à natureza primordialista dessa noção, já antes o autor havia escrito: "Nas suas origens e na sua essência, a identidade nacional é uma tentativa de preservar os 'costumes' dos nossos antepassados [...] O nacionalismo põe em destaque a necessidade das raízes e da tradição na vida de qualquer comunidade; evoca a 'posse comum de uma rica herança de recordações' (Renan)" (idem:11, ênfases minhas). "Preservar" e "necessidade" são, por assim dizer, as palavras-chave dessa concepção primordialista da identidade.

Atribuindo à Nação "o carácter sagrado que herdou da religião", Llobera conclui, em oposição radical às teses do primado empírico do Estado sobre qualquer identidade nacional, que "o grau de êxito das políticas de construção da nação projetadas pelo Estado está em relação direta com o maior grau de homogeneidade nacional étnica que existe em um país" (idem:289-290). Paradoxalmente, no mesmo livro onde o caso da Catalunha é abundantemente abordado no contexto ibérico, o autor considera que "o fato de Portugal se ter convertido em um estado independente e de ter permanecido como tal foi, em grande medida, o resultado de um acidente histórico" (idem:111-112).

É possível que assim tenha acontecido, mas essa conclusão não se limita a ferir as convicções dos nacionalistas portugueses, em contraste com a firme convicção do autor a respeito do "potencial etnonacional" da Catalunha, apesar de esta não ter logrado transformar esse "potencial" em Estado, nem na mesma altura em que o Estado português conseguiu recuperar sua autonomia em relação ao rei de Espanha no século XVII nem mais tarde. Estranhamente, o autor não utiliza uma única referência portuguesa clássica acerca da formação do Estado e da Nação portugueses, nem muito menos qualquer referência atualizada, como seria o caso de José Mattoso e António Hespanha (ver adiante). 
Na realidade, a visão que Llobera apresenta do caso português não só inverte radicalmente tudo quanto ele próprio afirmara acerca do papel subordinado do Estado na construção da Nação, como mostra que toda e qualquer concepção primordialista da identidade nacional entra, rapidamente, em flagrantes contradições sempre que muda de nação de referência: o que serve de "identidade" a umas nações parece já não servir a outras, pois, no caso português, o êxito do Estado nacional já não serviria como comprovação do potencial étnico, para usar as expressões do próprio Llobera. Não é por acaso que Renan, há pouco invocado por Llobera, confessava no próprio livro onde perguntava Qu'est-ce qu'une nation (1882): “O esquecimento e mesmo o erro histórico são factores essenciais na formação de uma nação, e é por isso que o progresso dos estudos históricos constitui um verdadeiro perigo para a nacionalidade" (Renan apud Guiomar, 1974:5).

Com efeito, já um autor como Paul Brass, embora reconhecendo "haver alguns aspectos da formulação primordialista com os quais não é difícil concordar", insistira simultaneamente em que

“[...] o estudo da etnicidade e da nacionalidade é, em larga medida, o estudo de mudanças culturais politicamente induzidas. Mais precisamente, é o estudo do processo através do qual as elites e contra-elites internas aos grupos étnicos selecionam determinados aspectos da cultura do grupo, atribuindo-lhes novo valor e significado, e usando-os como símbolos para mobilizar o grupo, defender os seus interesses e competir com outros grupos" (Brass, 1994:83-87).

Trata-se, em suma, de uma concepção bastante próxima à de Gellner, ao conceder ampla margem às contingências históricas e até geográficas na construção das identidades etnoculturais.

A verdade, porém, é que também não se pode dizer que a conhecida tese de Benedict Anderson (1993) sobre as "comunidades imaginárias" $^{3}$ - onde o autor procura de algum modo conciliar as concepções primordialistas com as concepções instrumentais da identidade nacional - tenha logrado superar de forma conclusiva a controvérsia sobre a primazia da Nação ou do Estado nos processos identitários mediante a tentativa de deslocar a ênfase do debate para as interações simbólicas e materiais entre comunidade e Estado na construção das identidades nacionais hodiernas. 
Algo de semelhante acontece, também, com a idéia da "invenção da tradição" proposta por Hobsbawm (1985), em que o autor propõe uma tese igualmente conciliatória sobre o papel do Estado na "atualização normativa" dos sentimentos nacionais, inclusive no âmbito das tradições lingüísticas e religiosas, habitualmente inscritas nas alegadas matrizes identitárias. No caso português, investigações recentes têm mostrado, efetivamente, que a difusão e padronização da língua portuguesa estão longe de ter precedido a constituição do Estado, havendo pelo contrário exigido freqüentes intervenções estatais no sentido de estabelecer normativamente a tradição, pelo menos desde o reinado de D. Dinis na viragem do século XIII para o século XIV (Marquilhas, 2000).

E não é necessário recordar que também a unidade religiosa da atual nação portuguesa não se fez sem a repressão promovida, recorrentemente, pela aliança entre o Estado e a Igreja católica, não só contra muçulmanos e judeus, mas também contra todas as manifestações da Reforma em Portugal; inversamente, só a apropriação do aparelho de Estado pela contra-elite liberal permitiu consagrar - e apenas de forma temporária e precária - a separação entre Igreja e Estado; nas antigas possessões ultramarinas portuguesas onde não houve colonização propriamente dita, ou seja, povoamento português, a influência cultural nacional ainda hoje observável se deve, freqüentemente, mais ao papel da Igreja do que ao do Estado e das instituições da sociedade civil.

Contas feitas, no presente estado da questão, sou tentado a ver em abordagens conciliadoras, como as de Anderson e Hobsbawm, as soluções disponíveis mais adequadas para o estudo sincrônico das identidades empíricas, desde que aceitemos abandonar ao indecidível histórico a sua dimensão diacrônica e, por maioria de razão, as suas origens fundacionais. Esse meio-caminho entre as concepções instrumental e primordial da identidade nacional é também retomado, além de Paul Brass, citado há pouco, por autores associados aos chamados estudos pós-coloniais, como Homi Bhabha (1990). Em contrapartida, que os defensores mais acérrimos do primado ontológico da Nação, no sentido de unidade etnocultural que atribuem ao termo, como Smith e Llobera, desqualificam as teses conciliatórias por cederem, em última instância, à primazia empírica do Estado na construção contingente das chamadas identidades nacionais. 


\section{GENEALOGIAS DA IDENTIDADE NACIONAL PORTUGUESA}

Para o caso da identidade nacional portuguesa, é basicamente uma abordagem conciliatória a adotada, por exemplo, por José Mattoso nos seus estudos sobre a identidade portuguesa. O autor não só resiste ao essencialismo identitário como chega a dar formalmente a primazia ao Estado no processo de construção da Nação, nomeadamente no seu recente livro sobre A Identidade Nacional: "O que cria e sustenta a identidade portuguesa é, de facto, o Estado" (Mattoso, 1998:82-83). Todavia, o autor também não deixa de interrogar-se, naquele e em outros trabalhos como medievalista especializado no período da formação do Estado português ao longo da primeira metade do século XII, sobre algo que se poderia designar, na linha do "potencial etnonacional" de Llobera, como a "existência de Portugal antes de Portugal", perguntando-se às vezes "se não seriam já 'portugueses' os habitantes do futuro Portugal"? (Mattoso, 1991; 1992).

Desde logo, porém, tais "portugueses" nunca seriam, do ponto de vista empírico e de acordo com o próprio Mattoso, mais do que os habitantes de uma estreita faixa territorial do Norte do país entre o rio Minho e o rio Douro, quando muito entre os rios Minho e Mondego, mas não incluiriam nem os habitantes de Lisboa nem, decididamente, os de todo esse vasto "Portugal mediterrânico" situado nas margens e a sul do rio Tejo (Silbert, 1966). Um argumento suplementar contra a concepção da nação como etnia residiria, apesar da naturalização da "nação portuguesa" decorrente da longa duração e da continuidade do Estado nacional, no fato de a sociedade portuguesa não constituir, manifestamente, do ponto de vista das tradições culturais, uma "etnia", mas sim várias, pelo menos duas, conforme se pode ainda ver, hoje em dia, através, por exemplo, dos mapas do comportamento eleitoral, maxime nas eleições presidenciais de 1986 e de 1996.

Com efeito, por força da drástica redução imposta pelo mecanismo da eleição presidencial em dois turnos, aí continuam a espelhar-se os dois grandes espaços culturais que estão na origem do território nacional, bem como as tradicionais clivagens a eles associadas, basicamente: Norte/Sul e campo/cidade, dobradas pelas diferenças induzidas pela evolução histórica da implantação do catolicismo e também pelas clivagens centro/periferia e proprietários/assalariados (Cabral, 1992). Aliás, do ponto de vista etnológico, nomeadamente da cultura material, esses "espaços" não seriam apenas dois, mas sim 
três de acordo com os estudos de Jorge Dias (1982) e de Orlando Ribeiro (1998). Porém, do ponto de vista sociocultural e, em particular, do ponto de vista político, são as "tensões entre um Norte tradicionalista e conservador e um Sul progressista e inovador" que sobressaem (Mattoso, 1998:79-81, maxime 80; 1991,II:215 e ss.). Com conotações ideológicas opostas, já Basílio Teles (1901) havia codificado no final do século XIX essa profunda clivagem política.

Por outras palavras, mesmo que fosse possível reconduzir ao Noroeste atlântico do Portugal atual um "potencial etnonacional" qualquer, todo o resto do território português - metade ou mais dele, incluindo a futura capital do reino - teria sido, por assim dizer, anexado e nacionalizado a partir de cima, do duplo ponto de vista territorial e simbólico, isto é, pela elite nortenha - guerreira e católica - capitaneada por Afonso Henriques e os seus sucessores próximos na chefia do Estado português recém-fundado.

Alternativamente, a par dessa tese de "segundo grau" sobre a construção da nacionalidade portuguesa, ainda se poderiam invocar os "fatores democráticos" na formação de Portugal outrora defendidos, embora talvez sem suficiente base empírica, por Jaime Cortesão - a saber, a "identidade marítima" das populações costeiras, piscatórias e embarcadiças, vivendo já então de costas mais ou menos viradas para o maciço continental ibérico: "A actividade marítima está não só nas raízes da nacionalidade, donde sobe como a seiva para o tronco, mas é como a linha medular que dá vigor e unidade a toda a sua história" (Cortesão, 1930:93).

Nessa mesma linha da argumentação "marítima e democrática", entroncaria, por exemplo, a conquista da Lisboa multiétnica e multicultural, para não dizer cosmopolita, e o papel da capital - no mínimo, coagulante primeiro, e liderante depois - na construção do Estado e, conseqüentemente, na nacionalização do território e das suas variegadas "etnias", para não falar do futuro papel de Lisboa como plataforma da expansão ultramarina (Mattoso, 1991, II:187-190).

Em suma, não creio que o debate geo-historiográfico acerca das origens da nacionalidade portuguesa permita decidir quanto a elas com qualquer segurança (ver por todos Ribeiro, 1987). O mesmo pode dizer-se dos fatores determinantes da prematura consolidação do Estado medieval português, a não ser que se trate do processo de "dupla 
contingência" a que está sujeita qualquer evolução societal, processo este que Luhmann (1994:103-136) entende como uma sucessão de opções contingentes - isto é, adotadas fora de qualquer determinismo, fosse ele o da "identidade nacional" dos atores relevantes - que não deixam, no entanto, de condicionar parcialmente o campo das opções futuras, abrindo uma e fechando outras simultaneamente.

No caso, isso significaria apenas que o êxito da formação do Estado português, mesmo que só em muito remota medida motivado pela eventual "existência de portugueses antes de Portugal", não poderia, quando consumado, deixar de fechar parcialmente o campo dos possíveis a opções futuras que excluíssem do seu horizonte a existência desse mesmo Estado e da correlativa formação de identidades sociais e pessoais em torno dele. Por outras palavras, independente do maior ou menor fundamento etno-cultural da identidade portuguesa, a mera existência do Estado nacional inviabiliza, por definição, quaisquer estratégias ou simples discursos negadores de uma identidade fundacional legitimadora de existência desse mesmo Estado. Assim, um mero "acidente histórico", como Llobera lhe chama, e talvez tenha sido, ter-se-á constituído em uma espécie de "necessidade de segundo grau".

\section{UMA "IDÉIA" DE PORTUGAL}

Em contrapartida, a prova dessa "necessidade" - por assim dizer, superveniente, ou seja, que só começa a ser sentida depois de o fator de satisfação ter sido criado - reside no avançado grau de elaboração já manifestado pelo sentimento de identidade nacional portuguesa por altura da crise sucessória de 1580, para não recuar às crônicas da crise similar do final do século XIV (Fernão Lopes, circa 1430). Com efeito, ao contrário do que crê Llobera, basta pensar em Os Lusíadas (1572) até por comparação com outras epopéias estrangeiras suas contemporâneas - para nos darmos conta desse elevado grau de elaboração da ideologia nacional, que se apresenta já com contornos muito próximos da forma definitivamente codificada no século XIX, com recurso aliás à própria celebração de Camões iniciada com Garrett e consumada pelo nacionalismo republicano ${ }^{4}$.

Embora restrita aos reduzidos círculos letrados da sociedade de então, o que não constitui de resto nada de anômalo, como Gellner demonstrou, a elaboração da identidade portuguesa não se limitava já 
às manifestações literárias, ganhando a sua reprodução particular alento com a "perda da independência nacional" para o rei de Espanha, Filipe II. A "idéia de Portugal" que é então elaborada, por exemplo, por um autor importante mas sem o relevo de Camões, como Fernando Oliveira, nos seus manuscritos inéditos do Livro da Antiguidade, Nobreza, Liberdade e Imunidade do Reino de Portugal e da História de Portugal, datados de 1579-1580, é um indício seguro da maturação, no seio da camada letrada da época, de uma consciência nacional cujas semelhanças com aquilo que hoje tomamos como a "identidade portuguesa" são flagrantes, tanto no plano da simbologia como no da argumentação política propriamente dita (Franco, 1999).

Naturalmente, desde a invocação da "antiguidade" à "imunidade" de Portugal, a retórica identitária de Fernando Oliveira visa, antes de mais, à construção de uma etnogenealogia, para usar a expressão de João Leal, destinada a combater o argumento do pretendente à Coroa de Portugal, Felipe II de Espanha, segundo o qual a "diferença entre Portugueses e Castelhanos não tem mais ser que um nome vão e falso, pois os espanhóis são uns como os outros e diferem tão pouco na língua, no trato e nos costumes" (idem, I:300 e ss.) $)^{5}$.

Ao mesmo tempo que faz recuar a existência de portugueses a "tempos imemoriais", o historiador quinhentista dessa comunidade imaginária não hesita em afirmar que, na sua História de Portugal: "A terra de Portugal digo que é livre, e é do povo natural dela, e os reis não são senhores dela, nem a podem vender, nem trocar, nem obrigar sem vontade do povo" (Oliveira apud Franco, 1999). Assim, a reivindicação de um "rei natural da terra" ultrapassa, com Fernando Oliveira, a questão dinástica para fazer depender a "eleição do rei" da pertença deste à alegada cultura dos habitantes do território nacional e à defesa dos seus interesses. Segundo Oliveira, já D. Afonso Henriques não teria assumido o trono português em virtude de uma "herança obrigatória", enquanto filho primogênito do conde portucalense D. Henrique, "senão por eleição do povo livre", isto é, pelos portugueses que, "vendo o muito detrimento que padeciam em companhia dos Castelhanos, determinaram apartar-se deles" (Oliveira apud Franco, 1999, I:355, passim). Franco parece, pois, ter alguns bons motivos para escrever: "Se, como refere Eduardo Lourenço, 'a auto-consciência nacional surge em João de Barros e é elevada à sua potência última por Camões' (Labirinto da Saudade), não será demasiado afirmarmos que 
ela transborda em Fernando Oliveira [...] que anuncia uma 'idéia' religiosamente devota da nação portuguesa" (Franco, 1999, I:311).

Bastante mais sóbria é, em contrapartida, a visão que fornecem Ana Cristina Nogueira da Silva e António Manuel Hespanha no balanço que fazem da identidade portuguesa na época da Restauração, em meados do século XVII: "Tudo isto faz com que os discursos seiscentistas sobre a identidade portuguesa apenas indiciem imaginários sectoriais, não permitindo globalizações válidas para toda a sociedade, nomeadamente a de um difuso sentimento patriótico, que explicaria, por exemplo, a Restauração [de 1640]". Segundo os autores, predominaria então "um imaginário social e político que realçava a multiplicidade e autonomia das distintas formas de solidariedade social e que distinguia cuidadosamente os correspondentes sentimentos de identidade": no topo, uma identidade da republica uchristiana; depois, "ainda acima da identidade nacional ou reinícola", existia a identidade "europeia" e, "muito mais forte", a "identidade hispânica" (Silva e Hespanha, 1993:19-37).

Por outro lado,

“[...] se por cima a identidade portuguesa tinha de conviver e que se cruzar com outras instâncias 'superiores' de classificação, o mesmo acontecia por baixo[, com] as identidades particulares [dos] parentes, patrícios e pares[; finalmente,] para além de uma identidade 'local' e 'regional' mais ou menos vincada, os Portugueses acumulavam depois, como é natural numa sociedade de estados, uma fortíssima identidade estatutária" (idem:20-29).

Quanto à "identidade reinícola", funcionava também - segundo os autores - "o sentimento de uma identidade política", cuja "manifestação mais directa e precoce é constituída, negativamente, pelo anti-castelhanismo", sendo citado para o efeito Duarte Gomes de Solís em 1621 (idem:29), mas já vimos que essa "identidade anti-castelhana" recuava, pelo menos, à crise sucessória de 1580. Já no século XVIII, com o advento do universalismo iluminista, ao mesmo tempo que a identidade portuguesa começa a ser objeto de um primeiro processo de desnaturalização, o problema desdobra-se, por assim dizer, sob efeito do choque entre castiços e estrangeirados. É bom não esquecer, contudo, que, segundo os autores que vimos acompanhando, "pelo menos até finais do século XVIII, a esmagadora maio- 
ria dos Portugueses não conhec[ia] uma representação gráfica do território do Reino" (idem:20).

Seja como for, enquanto os castiços crêem em uma identidade tradicional legítima e pugnam por um "constante esforço de repristinação de uma identidade primeva" (idem:19), os estrangeirados prolongam "uma linha de reflexão de origem humanista sobre os vícios dos Portugueses", cujo "resultado é uma consciência da identidade marcada pelo desencanto", o qual está, por seu turno, "na origem do decadentismo que caracteriza as correntes dominantes da cultura portuguesa durante os séculos XIX e XX" (idem:32-33)6. Em suma, um conflito identitário - por assim dizer, insuperável - que começou por ser protagonizado por castiços e estrangeirados no século XVIII e que ainda hoje tem ecos poderosos na sociedade portuguesa, com as respectivas bases regionais de apoio social e político, conforme referido há pouco a propósito das eleições presidenciais de 1986 e 1996.

\section{O CARÁTER NACIONAL PORTUGUÊS}

Em todo o caso, não será certamente a busca de qualquer "essência nacional portuguesa" - prosseguida sem descanso desde o advento do nacionalismo romântico até o seu congelamento pelos ideólogos do Estado Novo, culminando nos duvidosos "carateres nacionais" do etnólogo Jorge Dias - que nos ajudará muito a superar a controvérsia. Com efeito, não há nada que exponha mais a ideologia identitária a uma crítica devastadora do que as tentativas para ancorá-la em um pretenso "caráter nacional", com o seu drástico reducionismo e a sua paralela dimensão normativa: "Um misto de sonhador e de homem de acção [...] o Português é, sobretudo, profundamente humano, sensível, amoroso e bondoso, sem ser fraco" (Dias, 1971:19).

Previsivelmente, Jorge Dias, depois de reconhecer que "a origem da Nação se dev[e] também à política", sente a necessidade de acrescentar imediatamente que "a vontade do príncipe naturalmente se aproveitou de certas aspirações de independência latentes nas populações de Entre Douro e Minho" (ênfases minhas), para sustentar a seguir que a "curiosa particularidade [da] unificação e permanência da Nação portuguesa deve-se ao mar", conciliando assim todas as teses disponíveis - tanto as empíricas como as fundacionais - sobre a formação do chamado Estado-nação: "A força atractiva do Atlântico [...] foi a alma da Nação e foi com ele que se escreveu a História de Portugal". 
Dessa síntese demasiado eclética, que não dispensa a habitual alusão aos "Lusitanos" nem à "luta contra os mouros", brotará então uma idéia de "cultura portuguesa", cujo maior interesse reside nas especificações que Jorge Dias tem o cuidado de fazer a respeito das "culturas regionais" e, sobretudo, da dimensão restrita, para não dizer elitista, dessa cultura espartilhada entre o "local" e o "superior" (idem:12-17).

Quanto ao "caráter nacional" propriamente dito, o autor socorre-se de todos os estereótipos do repertório nacionalista, desde a "saudade" até o "manuelino", passando pela "brandura de costumes" e pela "inclinação por mulheres de outras raças", para terminar com uma conclusão banal e datada, mas nem por isso menos significativa na sua vácua circularidade: "É um povo paradoxal e difícil de governar. Os seus defeitos podem ser as suas virtudes e as suas virtudes os seus defeitos, conforme a égide do momento" (idem:33).

Apesar dessa insustentável vacuidade, João Leal mostrou recentemente que "a força do ensaio de Jorge Dias parece ser tal que a denúncia das suas teses" não impede autores atuais, como Boaventura Sousa Santos (notadamente nas suas "Onze Teses..." incluídas em Pela Mão de Alice de 1994), sempre que entram em diálogo com ele, em busca de uma fundação caracterial qualquer da identidade portuguesa, não só de incorrerem em uma "proximidade genérica difícil de desmentir" como de deixarem "o leitor atento perplexo" (Leal, 2000:101-104).

João Leal havia dito o mesmo, aliás, a respeito de José Mattoso, a propósito da sua Identidade nacional, o que lhe permite concluir com uma ponta de ironia: "Volvido quase meio século, os 'elementos fundamentais da cultura portuguesa' [retomados em O Carácter Nacional...] continuam a projectar a sua sombra nas discussões contemporâneas acerca do que é ser português". E algo de semelhante se passa também, segundo o autor, com Eduardo Lourenço e o tema da saudade. E por aí fora... com o grupo musical dos Madredeus (idem:103-104).

\section{CONTEÚDO E RELEVÂNCIA DO SENTIMENTO NACIONAL}

Pela minha parte, a inconsistência intrínseca de todo e qualquer conteúdo que se pretenda atribuir ao chamado "carácter nacional" leva-me, pois, a abandonar esse longo intróito em torno da genealogia 
da identidade portuguesa para adotar, doravante, um ponto de vista regressivo - isto é, de diante para trás - a fim de examinar essa mesma identidade a partir do ângulo sincrônico da observação sociológica empírica. Debruçar-me-ei assim sobre algo que me preocupa mais do que as origens do sentimento nacional, a saber: qual a sua relevância para o conhecimento e compreensão da sociedade portuguesa atual.

Com efeito, do ponto de vista do conteúdo, confesso não ver em que medida a identidade portuguesa se distingue da impenetrável mas banal circularidade dessa inevitável tautologia que é todo e qualquer nacionalismo - igual a todos os outros na reivindicação de uma diferença radical entre cada um deles, como creio que Gellner mostrou de uma vez por todas e como Llobera deixou entrever sem querer. Movendo-se embora no espaço e com a escala em que observador e observado se situem - por exemplo, no Brasil serei português; em Portugal açoriano; nos Açores micaelense; em S. Miguel serei da "cidade" [Ponta Delgada], e assim sucessivamente-, a verdade é que o conteúdo identitário não deixa de ser ontologicamente pobre, apetece mesmo dizer ensimesmado. Essa espécie de replicação, por assim dizer mimética, do sentimento identitário segundo a escala em que os indivíduos se situam está documentada para os Açores, por exemplo, em estudos empíricos com diversas sedes disciplinares (Leal, 2000:227-244; Mendes, 1999).

Isso não significa, como sabemos, que tal conteúdo não possa, apesar da sua pobreza ontológica, tornar-se criticamente relevante quando o imaginário nacional (ou regional: veja-se o caso açoriano) é ativado do exterior e, em especial, contra o exterior, mas pontualmente também contra o "interior", o que aponta para um conteúdo fatalmente não autônomo, para não dizer negativo, da chamada identidade nacional. É importante mencionar aqui a distinção, a meu ver muito pertinente para essa reflexão, que os maurrassianos e os "integralistas lusitanos" faziam entre patriotismo - isto é, a ativação de toda a população do país contra um inimigo externo, como terá acontecido pela primeira vez, historicamente, durante a Revolução Francesa, cunhando a expressão patriote - e o nacionalismo propriamente dito, isto é, a activação de uma parte da população contra os alegados "inimigos internos" da Nação ${ }^{7}$. É certo que a identificação de um ennemi de l'intérieur remonta à Revolução Francesa, designando então as forças internas que alegadamente se opunham à condução da guerra pelo Comitê de Salvação Pública; porém, a partir do final do século XIX, a 
expressão foi recuperada pela direita radical francesa a fim de designar indiferenciadamente os seus adversários políticos: liberais, democratas, socialistas, comunistas e outros anarquistas (Sternhell, 1978).

Porém, antes de tentar circunscrever a relevância do sentimento identitário, vale a pena fornecer um dado empírico atual e refletir por um momento acerca dele. Com efeito, todos os inquéritos sociológicos recentes nos quais é feita uma pergunta - obviamente redutora e descontextualizada - a respeito do espaço social com o qual os portugueses mais se identificam têm revelado, estranhamente ou não, um grau limitado de identificação com o espaço nacional. Embora estejam em maioria relativa, os inquiridos que se identificam prioritariamente com Portugal - sobretudo habitantes de Lisboa e populações do Sul não chegam, em geral, a metade da população; os outros inquiridos se distribuem sobretudo pelas suas "terras" - aldeias, vilas ou pequenas cidades - ou pelas suas regiões, principalmente no Norte em volta do Porto; por fim, há um resíduo de excêntricos, no duplo sentido da palavra, que dizem identificar-se prioritariamente com o espaço europeu ou mesmo universal.

Em um dos mais recentes desses inquéritos, realizado em 1997 junto de uma amostra representativa da população jovem portuguesa (15-29 anos de idade), os resultados foram os seguintes (Fernandes, 1998:311, Tabela 1):

\begin{tabular}{l|c}
\multicolumn{2}{c}{ Tabela 1} \\
\hline Lugar & $\%$ \\
Região & 16,6 \\
Portugal & 29,1 \\
Europa & 41,6 \\
Mundo & 4,7 \\
NS/NR & 4,4 \\
\hline
\end{tabular}

Fonte: Inquérito aos Jovens, ICS, 1997.

Por outras palavras, quando a identidade nacional não é ativada do exterior e o sentimento de pertença é referido à experiência quotidiana das pessoas, o que vem ao de cima é uma clivagem - pronunciadamente classista, aliás, sendo a distribuição aquela que os manuais de 
sociologia prevêem, segundo a qual a identidade nacional é um atributo das elites - entre múltiplos localismos e a identificação espontânea com a Nação. Só marginalmente poderei entrar aqui na questão da cidadania, mas bastará dizer que é significativa, do ponto de vista estatístico, a correlação inversa entre a força dos sentimentos de pertença local e um déficit, por vezes acentuado, do exercício dos direitos da cidadania democrática. Por outras palavras, quanto menor a identificação com o espaço nacional, menor também a propensão para o exercício da cidadania política (Cabral, 1997; 2000).

Em suma, por mais paradoxal que possa parecer em um país tão antigo como Portugal, com uma coincidência alegadamente perfeita entre Estado e Nação, a verdade é que o processo de nacionalização das populações - talvez devido aos profundos curtos-circuitos da cidadania, dependentes por seu turno dos atrasos da alfabetização de massas e do distanciamento entre estas e o poder político - encontra-se longe de estar completado em Portugal (Cabral, 2003). Por motivos históricos mal conhecidos e que não é possível aprofundar agora, o velho Estado português tem ainda muito que fazer no plano da "nacionalização das massas", lembrando às vezes a situação da França antes da Guerra de 1914-18 identificada por Eugen Weber (1976).

Com efeito, estudos clássicos, como o de Reinhard Bendix (1996:134 e ss.), há muito que assinalaram o papel da instrução pública básica na construção da cidadania ${ }^{8}$, bem como o contributo específico do sufrágio universal e secreto, que Portugal apenas conheceu há um quarto de século, para a transformação dos indivíduos em "cidadãos nacionais". Bendix chama a atenção, efetivamente, para a estreita associação histórica entre a formação das identidades sociais de caráter nacional - isto é, a concepção da cidadania como nacionalidade - e o desenvolvimento de uma identidade política, ou seja, da cidadania como pertença ativa a uma comunidade política nacional.

Nesse sentido, tem cabimento pensar que, para poder se falar plenamente de Estado-nação, isso implicaria a vivência nacional de uma "fusão entre autoridade e solidariedade" (Reis, 1996:21), segundo a qual o sentimento de pertença deixaria de ser passivo perante a autoridade do Estado para ser, também, ativo e solidário, graças à participação cívica e aos benefícios partilhados pelos cidadãos nacionais. Se à solidariedade quisermos acrescentar, como elemento da cidadania, conforme sugerido acima, a participação na cultura nacional através 
da instrução de massas, vale a pena recordar o que escrevia o insuspeito Jorge Dias a este respeito ainda em 1971: "Se existe uma cultura [portuguesa] com longa tradição, também é certo que são poucos os que nela participam, pois, por razões de educação e instrução, a maior parte da população recebe sobretudo a cultura tradicional da sua região" (Dias, 1971:13). A ser assim, é lícito argumentar que a plena assunção da "identidade nacional", por parte de numerosos estratos da população portuguesa, é bem mais recente, muito provavelmente, do que se poderia julgar à primeira vista.

\section{O PAPEL DO NACIONALISMO POLÍTICO EM PORTUGAL}

Para terminar, algumas breves reflexões sobre a efetiva relevância histórica da chamada identidade nacional, não só no plano das políticas interna e externa, como também no plano dos interesses materiais de alguns grupos sociais e, seguramente, no plano das identidades pessoais.

Latente, se não mesmo adormecido durante a maior parte do tempo, o sentimento nacional constitui, pois, um recurso ao dispor dos membros da comunidade, tanto para efeitos pessoais, como para a manutenção da identidade individual perante a emigração ou o exílio, por exemplo, experiências em que os portugueses são historicamente peritos, mas também para efeitos coletivos, como, por exemplo, o estabelecimento de redes grupais suscetíveis de trazerem benefícios econômicos, embora a população portuguesa ainda hoje se caracterize, sociologicamente, pelo primado das redes familiares e/ou clientelares (e só nesta medida "portuguesas"), na linha daquilo que alguns, como eu próprio, têm designado como o "familismo amoral" mas observações etnográficas pontuais de Jorge Dias a propósito do pretenso "carácter português" são, aliás, integráveis na noção de "familismo amoral", como, por exemplo, a "crença na sorte" e no "empenho ou pedido", bem como "a dificuldade [do funcionário público] em representar um papel impessoal"; até a pretensa "negação do espírito capitalista" que Jorge Dias atribui à cultura portuguesa é enquadrável nos termos do dito "familismo amoral" (idem:30-31). Em contrapartida, tais atitudes e comportamentos sociais não são mais "portugueses" do que "italianos", por exemplo, nem são obviamente comuns ao conjunto das respectivas populações nacionais. 
Mais gratuitas - puramente simbólicas, se tal coisa existe - são, por exemplo, as comoções identitárias coletivas induzidas, como Hobsbawm mostrou para o período da integração política das "massas" nos sistemas demo-liberais oitocentistas, pelos rituais celebratórios da pátria comum e, porventura mais inocentes ainda, os confrontos desportivos internacionais. Nada disso é, por si só, politicamente inócuo, como os promotores de tais eventos bem sabem e, hoje em dia, planeiam cuidadosamente, como quem reforça um reflexo comportamental.

Finalmente, mais relevante do que todas essas manifestações da identidade nacional é o fato de o sentimento nacional ter sido objeto, desde o último quartel do século XIX (e sem dúvida antes, mas apenas de forma incipiente e intermitente), de ativação política recorrente, seja pela oligarquia dominante contra alegados perigos externos ou, simplesmente, como fator de mobilização nacional perante desafios como, por exemplo, aquele a que Portugal vem respondendo diante da integração européia; seja ainda por um segmento das elites contra outros segmentos, como sucedeu com o movimento nacionalista autoritário que levou à tomada do poder por Salazar, entre 1928 e 1930, à institucionalização da ditadura do Estado Novo até à Guerra Colonial (iniciada em 1961) e, por fim, à prolongada agonia do regime consumada em 1974. Ao longo de todo esse penoso e conturbado percurso, a mobilização do sentimento de identidade nacional constituiu, sem a menor dúvida, uma das variáveis mais independentes da evolução política do país, apenas comparável ao papel das subidentidades das diversas camadas sociais que foram disputando à Ditadura o monopólio do "interesse nacional".

Assim se demonstra como algo de conteúdo afinal tão imaginário e tão pobre pode, de fato, produzir efeitos tão reais e tão relevantes para uma comunidade cujas diferenças são tanto mais críticas quanto têm de ser dirimidas, obrigatoriamente, no mesmo território com o qual toda essa comunidade se identifica. Daqui é lícito concluir que, sendo indiscutível a relevância de algo tão inefável como a identidade nacional, esta última é no entanto menos parte da solução, como promete a ideologia nacionalista, do que parte dos problemas que a Nação - na realidade, a Sociedade e o Estado - tem para resolver.

(Recebido para publicação em julho de 2003) (Versão definitiva em outubro de 2003) 


\section{Manuel Villaverde Cabral}

\section{NOTAS}

1. Sobre esse sistema de clivagens, ver o estudo clássico de Lipset e Rokkan (1967).

2. Pós-modernistas no sentido abrangente que lhes é conferido pela sua aspiração comum ao retorno à subjetividade contra os processos de objetivação característicos das ciências sociais modernistas, conforme sugere Le Bras (2000).

3. Prefiro a minha tradução à de "comunidades imaginadas", como é vulgar traduzir a expressão de Anderson.

4. A esse propósito, ver Cabral (1988). Para uma análise pormenorizada dos "exercícios de etno-genealogia" a que se dedicou, empenhadamente, a etnografia portuguesa desde finais do século XIX, ver Leal (2000: maxime cap. 2).

5. Carta de Felipe II de 1579.

6. A respeito da evolução da "ideologia portuguesa" do "decadentismo" à "salvação nacional", ver Cabral (1993).

7. Sobre essa questão do "inimigo do interior", cujo uso é aqui de inspiração tipicamente maurrassiana, ver Lyttelton (1975); para Portugal, ver Cabral (1988; 1993).

8. Se formos exigentes, de acordo por exemplo com as sugestões de Jack Goody (1987) em relação à "alfabetização restrita", a sociedade portuguesa só teria atingido o limiar da alfabetização de massas - digamos, mais de $50 \%$ da população adulta - depois da $2^{a}$ Guerra Mundial. Daqui, seguramente, muito do analfabetismo funcional que ainda hoje se observa em Portugal (Benavente, 1996).

9. Ver Cabral (2003), onde procuro reconstruir a noção original de "familismo amoral", cunhada pelo politólogo norte-americano Edward Banfield (1958) para caracterizar as atitudes e comportamentos de uma comunidade rural da Itália meridional; para o Brasil, ver Reis (1998).

\section{REFERÊNCIAS BIBLIOGRÁFICAS}

ANDERSON, Benedict. (1993), Imagined Communities: Reflections on the Origin and Spread of Nationalism. London/New York, Verso.

BANFIELD, Edward. (1958), The Moral Basis of a Backward Society. Glencoe, Ill., The Free Press.

BENAVENTE, Ana et alii. (1996), A Literacia em Portugal: Resultados de uma Pesquisa Extensiva e Monográfica. Lisboa, Fundação Calouste Gulbenkian/Instituto de Ciências Sociais.

BENDIX, Reinhard. (1996), Construção Nacional e Cidadania. São Paulo, EDUSP.

BHABHA, Homi. (1990), "Introdução", in H. Bhabha (org.), Nation and Narration. London, Routledge. 
BRASS, Paul. (1994), "Elite Competition and Nation Formation", in J. Hutchinson e A. D. Smith (eds.), Nationalism. Oxford, Oxford University Press.

CABRAL, M. V. (1988), "The Aesthetics of Nationalism: Literary Modernism and Political Authoritarianism in Portugal in the Early 20th Century". Luso-Brazilian Review, University of Wisconsin-Madison (publicado em português em N. S. Teixeira e A. C. Pinto (orgs.) (1998), A Primeira República Portuguesa entre o Liberalismo е о Autoritarismo. Lisboa, Colibri, pp. 181-211.

. (1992), “Portugal e a Europa: Diferenças e Semelhanças". Análise Social, vol. 27, no 118/119, pp. 943-954.

. (1993), The Demise of Liberalism and the Rise of Authoritarianism in Portugal, 1880-1930. Aula inaugural, Department of Portuguese, King's College London.

(1997), Cidadania Política e Equidade Social. Oeiras, Celta.

(2000), “O Exercício da Cidadania Política em Portugal”. Análise Social, no 154/155, pp. 85-113.

(2003), “O Exercício da Cidadania Política em Perspectiva Histórica (Portugal e Brasil)". Revista Brasileira de Ciências Sociais, vol. 18, no 51, pp. 31-60.

CORTESÃO, Jaime. (1930), “Os Factores Democráticos na Formação de Portugal”, in L. Montalvor (org.), História do Regime Republicano. Lisboa, vol. I, pp. 11-96.

DIAS, Jorge. (1971), Estudos do Carácter Nacional Português. Lisboa, Junta de Investigações do Ultramar.

_. (1982), Os Arados Portugueses e as suas Prováveis Origens. Lisboa, Imprensa Nacional.

FERNANDES, Ana Alexandre. (1998), "Identidade Nacional e Cidadania Europeia", in M. V. Cabral e J. M. Pais (orgs.), Jovens Portugueses de Hoje. Oeiras, Celta.

FRANCO, José Eduardo. (1999), A Ideia de Portugal em Fernando Oliveira: Posicionamentos em torno da Crise Sucessória de 1580. Dissertação de Mestrado, Faculdade de Letras da Universidade de Lisboa.

GELLNER, Ernest. (1993), Nações e Nacionalismo. Lisboa, Gradiva.

GOODY, Jack. (1987), The Interface between the Written and the Oral. Cambridge, Cambridge University Press.

GUIOMAR, J.-Y. (1974), L'Idéologie Nationale: Nation, Representation, Propriété. Paris, Editions Champ Libre.

HOBSBAWM, Eric J. et alii. (1985), The Invention of Tradition. Cambridge, Cambridge University Press.

LEAL, João. (2000), Etnografias Portuguesas (1870-1970). Cultura Popular e Identidade Nacional. Lisboa, Publicações Dom Quixote.

LE BRAS, Hervé. (2000), "Les Sciences Sociales entre Biologie et Politique”. La Recherche, $\mathrm{n}$ ㅇ 336, pp. 48-54.

LIPSET, S. M. e ROKKAN, S. (1967), “Estruturas de Clivagem, Sistemas Partidários e Alinhamentos dos Eleitores", in S. M. Lipset (1992), Consenso e Conflito. Lisboa, Gradiva. 


\section{Manuel Villaverde Cabral}

LLOBERA, Josep R. (1996), El Dios de la Modernidad. El Desarrollo del Nacionalismo en Europa Occidental. Barcelona, Editorial Anagrama.

LUHMANN, Niklas. (1994), Social Systems. Stanford, Stanford University Press.

LYTTELTON, Adrian (comp.). (1975), "Introdução", in Italian Fascisms from Pareto to Gentile. New York, Harper \& Row.

MARQUILHAS, Rita. (2000), A Faculdade das Letras. Lisboa, Imprensa Nacional.

MATTOSO, José. (1991), Identificação de um País: Ensaio sobre as Origens de Portugal, 1095-1325. Lisboa, Editorial Estampa (2 vols.).

_. (1992), Portugal Medieval: Novas Interpretações (2를. ed.). Lisboa, Imprensa Nacional. . (1998), A Identidade Nacional. Lisboa, Gradiva/Fundação Mário Soares.

MENDES, José Manuel. (1999), Do Ressentimento ao Reconhecimento: Valores, Identidades e Processos Políticos nos Açores (1964-1996). Tese de Doutorado, Faculdade de Economia, Universidade de Coimbra.

REIS, Elisa P. (1996), "Introdução", in R. Bendix, Construção Nacional e Cidadania. São Paulo, EDUSP.

. (1998), Processos e Escolhas. Estudos de Sociologia Política. Rio de Janeiro, Contra Capa.

RIBEIRO, Orlando. (1987), A Formação de Portugal. Lisboa, Instituto de Cultura e Língua Portuguesa.

. (1998), Portugal: O Mediterrâneo e o Atlântico: Esboço de Relações Geográficas (7ª ed.). Lisboa, Sá da Costa.

SILBERT, Albert. (1966), Le Portugal Méditerranéen à la fin de l'Ancien Regime du XVIIIe au Début du XIXe Siècles: Contribution à l'Histoire Agraire Comparée. Paris, SEVPEN.

SILVA, Ana Cristina Nogueira da e HESPANHA, António Manuel. (1993), “A Identidade Portuguesa", in A. M. Hespanha (coord.), O Antigo Regime - vol. IV da História de Portugal, dirigida por José Mattoso. Lisboa, Círculo de Leitores, pp. 19-37.

SMITH, Anthony D. (1986), The Ethnic Origins of Nations. Oxford, Blackwell.

STERNHELL, Zeev. (1978), La Droite Révolutionnaire, 1885-1914: Les Origines Françaises du Fascisme. Paris, Editions du Seuil.

TELES, Basílio. (1901), Estudos Históricos e Económicos. Porto, Chardron.

WEBER, Eugen. (1976), From Peasants into Frenchmen: The Modernization of Rural France, 1870-1914. Stanford, Stanford University Press. 


\begin{abstract}
Portuguese National Identity: Content and Relevance

This article discusses the relative merits of the instrumentalist and primordialist theses concerning the roles of the State and the nation in the production of contemporary national identities, as well as presenting a brief genealogy of Portuguese national identity. However, the attempt to anchor this identity in a purported "national character" reveals the reductionism and normative dimension of identitary ideology. The research is thus reoriented towards the relevance of national sentiment in current Portuguese society, observing that this sentiment constitutes a relevant symbolic resource, particularly for purposes of political mobilization.
\end{abstract}

Key words: identity; state; nation; Portugal

RÉSUMÉ

L'Identité Nationale Portugaise: Contenu et Importance

Dans cet article, on discute les avantages relatifs des thèses instrumentalistes et primordialistes à propos du rôle de l'État et de la Nation dans la production des identités nationales contemporaines tout en présentant une rapide généalogie de l'identité portugaise. Toutefois la tentative de rattacher celle-ci à un supposé "caractère national" révèle le réductionisme et la dimension normative de l'idéologie identitaire. La recherche est donc réorientée par l'importance du sentiment national dans la société portugaise actuelle, puisqu'on se rend compte que ce sentiment s'avère un recours symbolique considérable, surtout lorsqu'il débouche sur une mobilisation politique.

Mots-clé: identité; État; nation; Portugal 